\title{
Anticholinesterase and acaricidal activities of steroids isolated from Trianthema portulacastrum L. against Rhipicephalus annulatus tick
}

\author{
Abeer Moawad ${ }^{1}$, Hala Abuzaid ${ }^{1,2}$, Waleed M Arafa ${ }^{3}$, Osama Ahmed ${ }^{4}$, Mona Hetta ${ }^{5}$, Rabab Mohammed $^{1 *}$ \\ ${ }^{1}$ Department of Pharmacognosy, Faculty of Pharmacy, Beni-Suef University, Beni-Suef, Egypt. \\ ${ }^{2}$ Department of Pharmacy, Ministry of Health, Beni-Suef, Egypt. \\ ${ }^{3}$ Department of Parasitology, Faculty of Veterinary Medicine, Beni-Suef University, Beni-Suef, Egypt. \\ ${ }^{4}$ Department of Zoology, Physiology Division, Faculty of Sciences, Beni-Suef University, Beni-Suef, Egypt. \\ ${ }^{5}$ Department of Pharmacognosy, Faculty of Pharmacy, Fayoum University, Fayoum, Egypt.
}

\begin{tabular}{l}
\hline ARTICLE INFO \\
\hline Received on: 29/05/2019 \\
Accepted on: 02/03/2020 \\
Available online: 04/04/2020 \\
\hline Key words: \\
Aizoaceae, Trianthema \\
portulacastrum, Aizoon \\
canariensis, Rhipicephalus \\
annulatus, Steroids, \\
Anti-acetylcholinesterase.
\end{tabular}

\section{INTRODUCTION}

Cattle raising is one of the most important sectors of the Egyptian agribusiness and consequently of the national economy. Rhipicephalus annulatus represents a major risk factor for the cattle industry in Egypt (Aboelhadid et al., 2016). Tick transmits crucial pathogens for cattle, including Babesia and Anaplasma species (Ferreira et al., 2018). Since the use of commercial drugs

\section{"Corresponding Author}

Rabab Mohammed, Department of Pharmacognosy,

Faculty of Pharmacy, Beni-Suef University, Beni-Suef, Egypt.

E-mail:rmwork06@yahoo.com

\begin{abstract}
The anticholinesterase and acaricidal activities of two plants of family Aizoaceae; Trianthema portulacastrum L. and Aizoon canariensis L. against Rhipicephalus annulatus tick were performed. Acaricidal activity was evaluated using adult and larval immersion tests of different concentrations (12.5, 25, 50, 100, and $150 \mathrm{mg} / \mathrm{ml})$. Antiacetylcholinesterase activity of plant extracts and isolated compounds were performed spectrophotometrically using showed $100 \%$ adult and larval mortality, while $A$. canariensis L. showed only $20 \%$ and $25 \%$, respectively $(p \geq 0.05)$. The bioassay-guided fractionation of T. portulacastrum hydroalcoholic extract was performed for the acaricidal activity and both $n$-hexane fraction and the unsaponifiable matter (USM) retained a significant activity in immersion tests. Its column chromatography (CC) led to the isolation of a $\beta$-sitosterol (1)-stigmasterol (2) mixture (1:1). Ethyl etate (EA) fraction showed $70 \%$ adult mortality and the compound 20 -hydroxyecdysone (3) was isolated as a major compound. The hydroalcoholic extract of T. portulacastrum, hexane fraction, and 20-hydroxyecdysone (3) produced the most potent inhibitory effect on acetylcholinesterase (AChE). In conclusion, T. portulacastrum L. contains secondary metabolites with acaricidal activities that provide promising natural products for controlling bovine tick. These acaricidal effects may be mediated, at least in part, via AChE inhibitory activities.
\end{abstract}

involves many problems, including drug-resistance shown by the most important parasites, the environmental damage, and the toxicity (Flamini, 2003); therefore, the direct application of effective plant extracts is a big demand to substitute the synthetic acaricides (Chungsamarnyart and Jansawan, 2001).

The use of the plant extracts, essential oils, and their major constituents for the control of several external and internal parasites have been carried out in different studies. The tested parasites were, for example, house dust mite (El-Zemity et al., 2006), mosquitos including Anopheles culicifacies, Anopheles stephensi, Culex quinquefaciatus, Aedes aegypti (Jayaraman et al., 2015), and sheep nematodes (Hussain et al., 2011), and different ticks, including Amblyomma americanum, Dermacentor variabilis, Ixodes scapularis, Rhipicephalus sanguineus (Flor- 
Weiler et al., 2011), Hyalomma dromedarii (Al-Rajhy et al., 2003), and R. annulatus (Moawad et al., 2017).

The inhibition of acetylcholinesterase (AChE) enzyme is the mode of action of organophosphate and carbamate pesticides consequently increasing neuronal excitation caused by acetylcholine which is followed by paralysis and death of the parasite (Tan et al., 2011). Some studies focused on measuring the in vitro acaricide and anticholinesterase activities to find a direct relation. The $n$-hexane extract of Calea serrata had acaricidal activity against larvae of Rhipicephalus (Boophilus) microplus and inhibition of AChE is a possible mechanism of action (Ribeiro et al., 2012). It was also reported that the AChE inhibitory activity of stigmasterol and hexacosanol is responsible for larvicidal and repellent properties of Chromolaena odorata (Gade et al., 2017). In the same regard, Santos et al. (2018) found that the hexanic and ethyle acetate extracts and hexanic extract fraction two obtained from the leaves of Digitaria insularison induced significant inhibition of AChE activity and acaricidal activity. Many other studies have revealed that the effect against AChE was implicated in the acaricidal mechanisms of many plant constituents and extracts ( Abdelgaleil et al., 2019; Badawy et al., 2010; Van Leeuwen et al., 2010).

Aizoaceae family has many plants with reported antifungal, antibacterial activity (Mohammed et al., 2012), acaricidal activity against $R$. annulatus (Moawad et al., 2017). Trianthema portulacastrum $\mathrm{L}$. is a potential traditional herb belongs to the family Aizoaceae. It is rapidly growing, annual terrestrial weed. It showed interesting antiparasitic activities, including anthelmintic activity against sheep nematodes (Hussain et al., 2011) and also mosquito larvicidal activity against Anopheles culicifacies, Anopheles stephensi, Culex quinquefaciatus, and Aedes aegypti (Singh et al., 2011). Traditionally, it is also used for the treatment of various diseases, such as stomachic, laxative, analgesic, antianemia, antiulcer, and abortifacient (Yadav et al., 2016).

Aizoon canariensis is a perennial plant belonging to the family Aizoaceae. It is distributed in North Africa, Mediterranean, south Iran, Afghanistan, and Pakistan (Freije et al., 2013). It has poor literature concerning its chemical constituents and biological uses.

From the previously reported antiparasitic properties of Aizoaceae plants and previous reports about $T$. portulacastrum against internal and external parasites, it is interesting to evaluate the anticholinesterase and acaricidal activity of $T$. portulacastrum L. and A. canariensis against adult and larvae of $R$. annulatus tick.

\section{MATERIALS AND METHODS}

\section{Materials for chromatographic study}

Silica gel for column chromatography (CC) (E. Merck), Pre-coated silica gel $\mathrm{G}_{60} \mathrm{~F}_{254}$ thin layer chromatography (TLC) plates $(20 \times 20 \mathrm{~cm})$ (Pharmacia Biotech AB, Uppsala). Solvents for chromatography were of analytical grade. Steroids were visualized by spraying TLC with $p$-anisaldehyde's reagent, followed by warming with a heat gun. The chemical acaricide deltamethrin $50 \mu \mathrm{g} / \mathrm{ml}$ (Butox ${ }^{\circledR} 50$ Intervet International, The Netherlands) was used as a positive control. Fifty percent DMSO-EtOH was used as a vehicle for preparation of extracts for the acaricidal study. AChE, acetylthiocholine iodide, and 6, 6'-Dinitro-3, 3'-dithiodibenzoic acid were obtained from Sigma
Chemical Company (Saint Louis, MO). All other chemicals are commercially obtained and are of analytical grade.

\section{Nuclear magnetic resonance spectrometry}

Nuclear magnetic resonance (NMR) was used for identification of steroids. Spectra were recorded using a Bruker Avance III $400 \mathrm{MHz}$ (Bruker AG, Switzerland) with AEON Nitrogen-Free Magnet and BBFO Smart Probe. Data acquisition and processing was performed using Topspin 3.1 Software. $\mathrm{CDCl}_{3}$, an NMR solvent, was purchased from Cambridge Isotope Laboratories, Inc., (Andover, MA).

\section{Plant material}

Entire herbs of $T$. portulacastrum L. (TP) and $A$. canariensis L. (AC) were collected and identified by Prof. Dr. Abdel Haleem Abdel Motagaly, Agriculture Museum, Giza, Egypt in the flowering stage in spring and summer 2015 and 2017, from Cairo - Suez Canal road, East desert, Egypt. The voucher specimen's numbers (R-Trian-10) and (R-Aizo) given to T. portulacastrum L. and A. canariensis L., respectively, and deposited at the Botanic Herbarium, Agriculture Museum, Dokky, Egypt.

\section{Preparation of plant extracts}

\section{Extraction}

A small-scale extraction for preliminary screening is done for both plants. Fifty grams of each plant material were separately extracted with $70 \%$ ethanol to prepare the crude hydroalcoholic $(\mathrm{CH})$ extracts. TP was found active while AC wasn't so; largescale extraction was performed for TP. A kilogram powder was successively extracted with $70 \%$ ethanol $(3 \times 3 \mathrm{~L})$. TP-CH extract was concentrated in vacuum using rotary evaporator at $40^{\circ} \mathrm{C}$. The residue (116 g) was suspended in distilled water and was subjected to solvent partitioning using $n$-hexane (HX) $(3 \times 500 \mathrm{ml})$, ethyl acetate $(\mathrm{EA})(4 \times 300 \mathrm{ml})$, and $n$-butanol (BT) $(3$ times $\times 200$ $\mathrm{ml})$. All solvents were dried under vacuum and the extract yields are shown in Figure 2. Five concentrations were prepared from different extracts $(12.5,25,50,100$, and $150 \mathrm{mg} / \mathrm{ml})$ in $50 \%$ DMSO-EtOH as a vehicle. The prepared concentrations were applied on adult ticks and unfed larvae.

\section{Preparation of USM}

Ten gm of $n$-hexane extract was saponified by refluxing

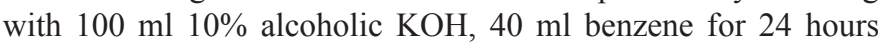
(Kamal et al., 2017). After distillation of ethanol and benzene and dilution with water, the USM was extracted with ether till exhaustion to yield $1.5 \mathrm{~g}$ USM.

\section{Isolation of the fatty acids from the saponifiable fraction}

The aqueous mother liquor, left after extraction of USM, was acidified with $10 \% \mathrm{HCl}$ and the liberated fatty acids were extracted with ether till exhaustion to yield $1.5 \mathrm{~g}$ FAs (Christie, 1993).

Chromatographic isolation of $\boldsymbol{T}$. portulacastrum $\mathrm{L}$. secondary metabolites

USM (3 g) was fractionated on Vacuum Liquid Chromatography (VLC) using silica gel for column (90 g, $25 \times 3.5$ 
$\mathrm{cm}$ ) eluted with petroleum ether (PE) and increasing the polarity by adding 5\% increments of EA and collecting $100 \mathrm{ml}$ fractions. TLC using HX-EA (8:2) and spraying with $p$-anisaldehyde's reagent followed by heating was done to collect similar subfractions. The subfraction eluted with PE-EA (90:10 to 80:20) (1.250 g) was chromatographed on silica column $(30 \mathrm{~g}, 28 \times 2 \mathrm{~cm})$ eluted with PE-EA with $1 \%$ increments to give $400 \mathrm{mg}$ white powder. The powder was found to be a $(1: 1)$ mixture of $\beta$-sitosterol and stigmasterol as shown by1D-NMR spectroscopy including ${ }^{1} \mathrm{H}$ and ${ }^{13} \mathrm{CNMR}$ spectra and comparison with literature (Chaturvedula and Prakash, 2012) and (Amin et al., 2017). EA extractive (3 g) was chromatographed over silica column $(90 \mathrm{~g}, 88 \times 2 \mathrm{~cm})$. Elution was performed with $\mathrm{MeOH} / \mathrm{CH}_{2} \mathrm{Cl}_{2}$ in gradient elution with $5 \%$ increment of $\mathrm{MeOH}$ and collecting $10 \mathrm{ml}$ fractions. TLC of the fractions was done and similar ones were combined to get $100 \mathrm{mg}$ yellow residue eluted with $15 \% \mathrm{MeOH} / \mathrm{CH}_{2} \mathrm{Cl}_{2}$ was rechromatographed on Sephadex $-\mathrm{LH}_{20}$ column eluted with $\mathrm{MeOH}$ to give compound (3) (20 mg). Compound (3) was found to be 20-hydroxyecdysone by1D-NMR spectroscopy, including ${ }^{1} \mathrm{H}$ and ${ }^{13} \mathrm{CNMR}$ spectra and comparison with literature (Girault and Lafont, 1988) which was the major steroid in EA and BT fractions. The amount isolated from 20-hydroxyecdysone was not sufficient for immersion test and only AChE inhibition test was performed on it. The structure of isolated compounds are shown in Figure 1.

\section{AChE assay}

AChE percent inhibition was detected based on the methods of Ellman et al. (1961) and Akkol et al. (2012) with little modification. The plant extracts, fractions, and constituents were dissolved in dimethyl sulphoxide (DMSO). Briefly, the test sample was prepared by adding $3 \mathrm{ml}$ phosphate buffer $(\mathrm{pH}=8)$, $0.1 \mathrm{ml} \mathrm{AChE}$ source (600 Units $/ \mathrm{ml})$ diluted 1:120, $100 \mu \mathrm{l}$ plant extract, fraction, or constituent (dissolved in DMSO), and $20 \mu \mathrm{l}$ acetylthiocholine iodide $(0.075 \mathrm{M})$ in Wassermann tubes. The absorbance was measured just after addition and mixing at 15

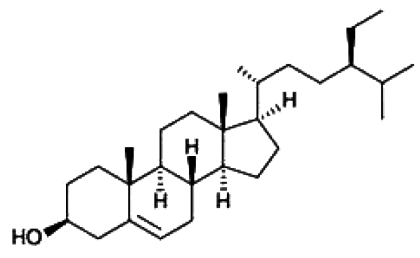

$\beta$-sitosterol

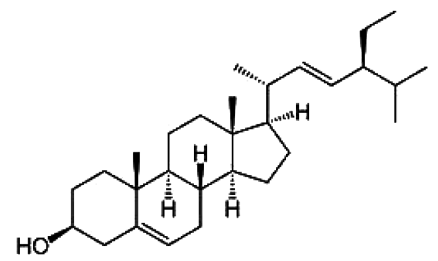

Stigmasterol

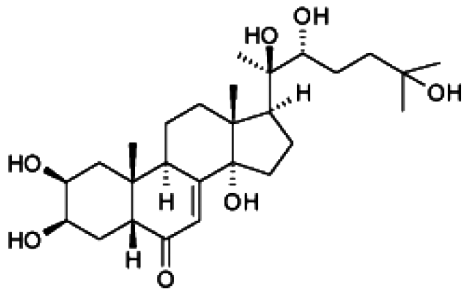

20-hydroxyecdysone

Figure 1. Structure of steroids isolated from T. portulacastrum L herb. minutes and $\Delta \mathrm{A}$ was calculated for each test sample. Blank test was prepared by using $100 \mu \mathrm{D}$ DMSO instead of the plant extract, fraction, or constituent, and $\Delta \mathrm{A}$ for blank was also calculated in the same way. The percentage of inhibition of AChE was determined by applying the following equation: $\mathrm{AChE}$ percent inhibition $=100-[\Delta \mathrm{A}$ for sample $/ \Delta \mathrm{A}$ for blank $] \times 100$. Three final concentrations $(0.25,0.5$, and $1 \mathrm{mg} / \mathrm{ml})$ were used for each plant extract, fraction, or constituent, and three triplicates were applied for each concentration. A standard drug, galantamine, was used at the same concentrations.

\section{Acaricidal study}

\section{Sampling of $R$. annulatus}

The collection of fully engorged female $R$. annulatus ticks was performed during Summer 2017 from naturally infested cattle making sure that they had not received any tick treatments for at least 20 days according to Rodriguez-Vivas et al. (2006). The ticks were kept in clean plastic bottles with lids containing small holes. The collected ticks were transported to the Parasitology Laboratory, Faculty of Veterinary Medicine, BeniSuef University for identification and experimental application. The freshly collected females were separated, carefully washed, and then dried on an absorbent paper. Engorged females weighing not less than $140 \mathrm{mg}$ with no signs of injury were used in the study.

\section{Adult immersion test (AIT)}

AIT was performed as described by Sharma et al. (2012) with little modifications. Ticks were divided into 10 groups (10 ticks each) to evaluate the activity of TP and AC extracts and TP major compounds. The groups were: negative control group $(50 \%$ DMSO-EtOH), AC CH extract, and TP $\mathrm{CH}$ extract. TP-hexane fraction, TP-EA fraction, TP-butanol fraction, TP USM, TP-fatty acids, $\beta$-sitosterol-stigmasterol mixture, and finally the positive control deltamethrin $(50 \mu \mathrm{g} / \mathrm{ml})$. All experiments were done in triplicates in clean-labeled Petri dishes. The different groups of ticks were immersed in $5 \mathrm{ml}$ of each treatment. After 2 minutes, the liquid was poured off and the ticks were transferred to a filter paper for drying and then kept separately in clean Petri dishes. Simultaneously, the ticks in the control group were treated with $50 \%$ DMSO-EtOH. The treated ticks were kept in biochemical oxygen demand (B.O.D.) incubator at a temperature of $27 \pm 2^{\circ} \mathrm{C}$ and relative humidity of $80 \pm 10 \%$. The mortality was recorded after 72 -hour post treatment. Mortality $\%=($ number of dead tick in treated groups-number of dead tick in control groups) $\times 100 /$ Total number of treated ticks. Oviposition was estimated by measuring the weight of eggs (mg) laid by each group (10 females).

\section{Larval immersion test (LIT)}

The different concentrations of the products were screened against the unfed (15-day old) larvae. One milliliter of each solution was transferred to $1.5 \mathrm{ml}$ microcentrifuge tubes and then approximately 100 larvae were added to each one. Control solutions were prepared adding one $\mathrm{ml} \mathrm{50 \%} \mathrm{DMSO-EtOH.}$ Immediately after addition of larvae, tubes were closed and shaken vigorously for 30 seconds and then gently for 10 minutes (Klafke et al., 2006). The tubes were then opened, and the larvae transferred with a paint brush to a filter paper. After drying, paper was folded and closed with clips forming a packet. The packets 


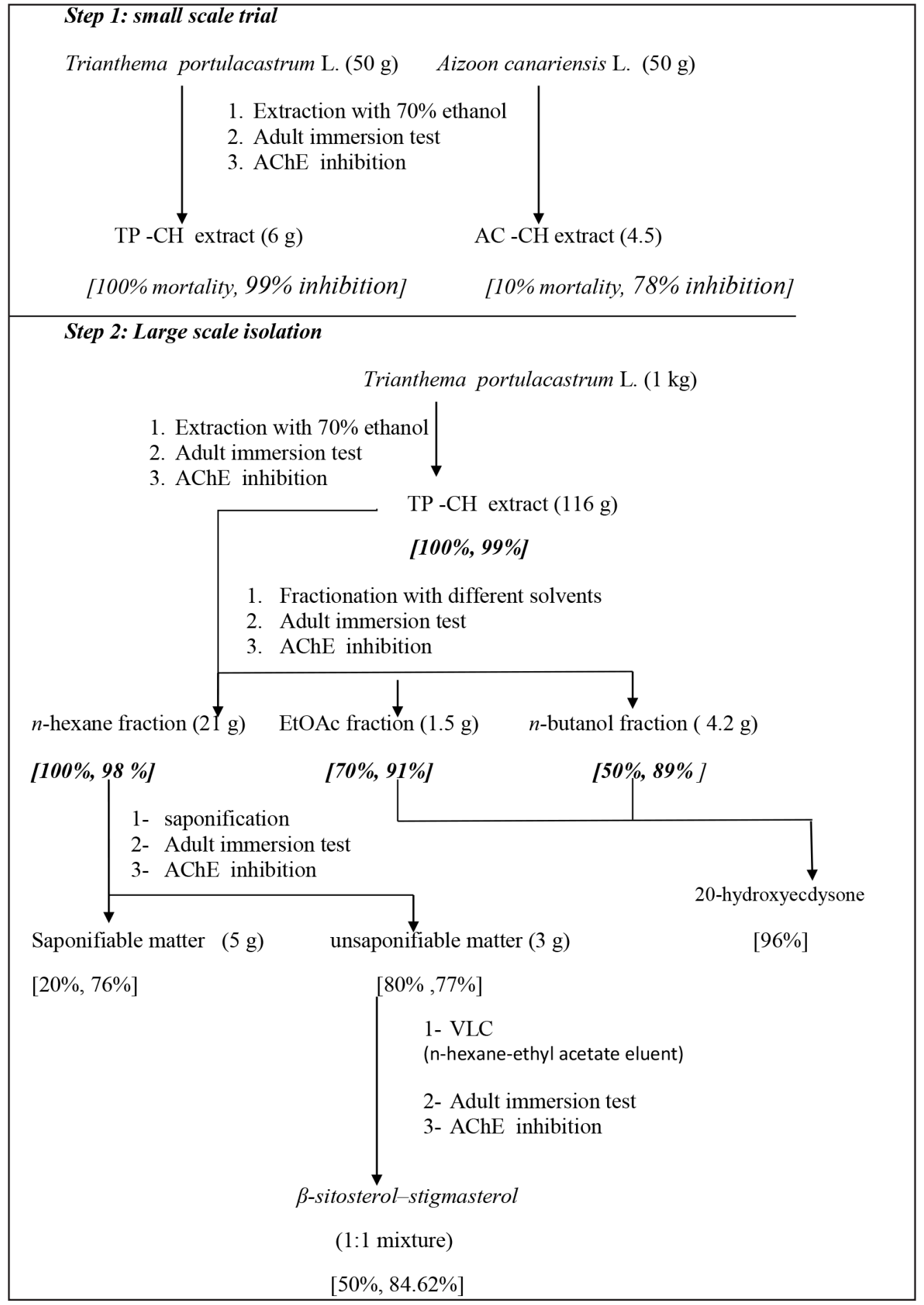

Figure 2. Scheme for bioassay-guided isolation of acaricidal steroids from Trianthema protulocastrum; $\%$ mortality of adult tick followed by \% inhibition of AChE are between brackets.

were incubated at $27^{\circ} \mathrm{C}-28^{\circ} \mathrm{C}$ and $80 \%-90 \%$ relative humidity for 24 hours, and then the mortality was determined.

\section{Statistics}

For acaricidal study, statistical analysis of data was performed using Statistical Package for Social Science (SPSS for Windows (IBM), version 22, Chicago, IL) to determine if variables differed between treatments. ANOVA tests and subsequent Duncan's multiple range tests were applied to determine the differences between means. Results were presented as means. Probability values of less than $0.05(p<0.05)$ was considered as significant. The effective concentration (EC50) with $95 \%$ Confidence Interval $(95 \% \mathrm{CI})$ was calculated by non-linear regression and probit analysis (SPSS version 22). For AChE, 
ANOVA followed by least significant difference (LSD) test were applied for the analysis of data by using the IBM SPSS version 22 and PC-STAT programs.

\section{RESULTS}

The two plants of the family Aizoaceae: TP and AC were assessed for potential acaricidal activity against $R$. annulatus tick using immersion tests and the anticholinesterase activity to find a mechanism for the acaricidal activity.

\section{The effect of the used materials on adult $R$. annulatus}

The $\mathrm{CH}$ extracts of both plants were tested. Mortalities and deposited egg mass of $\mathrm{AC}-\mathrm{CH}$ group against $R$. annulatus ticks were non-significantly different from negative control group even at its highest concentration, (Table 1).

On the contrary, TP-CH extract showed significant mortalities at 100 and $150 \mathrm{mg} / \mathrm{ml}$ that showed non-significant difference with deltamethrin-treated group; ticks died quickly without egg deposition and showed black coloration and shrinkage of the cuticle. Also, egg mass was reduced significantly $(p \leq 0.05)$ in concentrations 50,25 , and $12.5 \mathrm{mg} / \mathrm{ml}$ compared to untreated control group (Table 1).

In TP-HX group, the highest two concentrations (100 and $150 \mathrm{mg} / \mathrm{ml}$ ) achieved the same adulticidal findings of TP$\mathrm{CH}$ extract. At $50 \mathrm{mg} / \mathrm{ml}$ concentration; TP-HX showed $70 \%$ mortalities which still significantly different from negative control group, while the lower concentrations were not. TP-HX was the most active among $\mathrm{CH}$ fractions, so saponification was done to prepare USM and FA fractions.

TP-USM achieved $85 \%$ adult mortality at $50 \mathrm{mg} /$ $\mathrm{ml}$, while TP-FA achieved only $20 \%$ mortality at the same concentration. Egg mass was insignificant from deltamethrin group in TP-USM, while in TP-FA it was insignificantly different from negative control group. TP-USM showed significant adulticidal activity at $p \leq 0.05$; Therefore, GC-MS analysis was performed, and chromatographic isolation was done.

Table 1. Adult mortality, egg mass and larval mortality of adult females of Rhipicephalus annulatus tick exposed to the immersion test with the extracts and fractions of $\mathrm{AC}$ and $\mathrm{TP}$

\begin{tabular}{|c|c|c|c|c|c|c|}
\hline \multirow{2}{*}{ Treatment } & \multirow{2}{*}{$\begin{array}{c}\text { Concentration } \\
\mathrm{mg} / \mathrm{ml}\end{array}$} & \multicolumn{3}{|c|}{ Adult } & \multicolumn{2}{|c|}{ Larva } \\
\hline & & Mortality \% & $\mathbf{E C}_{50}$ & Oviposition(mg) & Mortality \% & $\mathbf{E C}_{50}$ \\
\hline \multirow{2}{*}{$\mathrm{AC}-\mathrm{CH}$} & 150 & $20 \pm 0.0^{\mathrm{a}}$ & - & $300 \pm 0.00^{j}$ & $25 \pm 0.0^{\mathrm{a}}$ & - \\
\hline & 100 & $0 \pm 0.0^{\mathrm{a}}$ & - & $350.0 \pm 0.0^{\mathrm{j}}$ & $0 \pm 0.0^{\mathrm{a}}$ & - \\
\hline \multirow{5}{*}{ TP-CH } & 150 & $100 \pm 0.0^{\mathrm{e}}$ & & $0^{\mathrm{a}}$ & $100 \pm 0.0^{\mathrm{d}}$ & \multirow{5}{*}{$24 \mathrm{X}^{2} 6.4^{*}$} \\
\hline & 100 & $90 \pm 1.0^{\mathrm{e}}$ & & $86.7 \pm 5.7^{\mathrm{d}}$ & $96.7 \pm 2.9^{d}$ & \\
\hline & 50 & $36.7 \pm 3.7^{\mathrm{b}}$ & $69.4 \mathrm{X}^{2} 6.4^{*}$ & $160 \pm 0.0^{\mathrm{g}}$ & $96.7 \pm 2.9^{d}$ & \\
\hline & 25 & $40.0 \pm 2.6^{\mathrm{b}}$ & & $270 \pm 0.0^{\mathrm{i}}$ & $50.0 \pm 0.0^{\mathrm{c}}$ & \\
\hline & 12.5 & $26.7 \pm 2.0^{\mathrm{b}}$ & & $260.7 \pm 1.1^{\mathrm{i}}$ & $20.0 \pm 0.0^{\mathrm{a}}$ & \\
\hline \multirow{7}{*}{ TP-HX } & - & - & & - & $100 \pm 2.9^{d}$ & - \\
\hline & 150 & $100 \pm .00^{\mathrm{e}}$ & & $0^{\mathrm{a}}$ & $100 \pm 0.0^{\mathrm{d}}$ & - \\
\hline & 100 & $90 \pm 0.0^{\mathrm{e}}$ & & $8 \pm 0.0^{\mathrm{a}}$ & \multirow{3}{*}{$70 \pm 0.0^{\mathrm{c}}$} & \multirow{3}{*}{$34.6 \mathrm{X}^{2} 10.9^{*}$} \\
\hline & 50 & $70 \pm 0.0^{\mathrm{d}}$ & $45.7 \mathrm{X}^{2} 7.9^{*}$ & $60 \pm 0.0^{c}$ & & \\
\hline & 25 & $20 \pm 0.0^{\mathrm{a}}$ & & $120 \pm 0.0^{\mathrm{f}}$ & & \\
\hline & \multirow{2}{*}{12.5} & \multirow{2}{*}{$16.6 \pm 1.2^{\mathrm{a}}$} & & \multirow{2}{*}{$120 \pm 0.0^{\mathrm{f}}$} & $50 \pm 0.0^{\mathrm{b}}$ & - \\
\hline & & & & & $20 \pm 0.0^{\mathrm{a}}$ & - \\
\hline \multirow{5}{*}{ TP-EA } & 150 & $70 \pm 0.0^{\mathrm{d}}$ & & $43.3 \pm 31.8^{b}$ & $70.0 \pm .00^{\mathrm{c}}$ & \multirow{5}{*}{$114.7 \mathrm{X}^{2} 2.6^{*}$} \\
\hline & 100 & $50 \pm 0.0^{\mathrm{c}}$ & & $90 \pm 0.0^{\mathrm{d}}$ & $50.0 \pm .00^{\mathrm{b}}$ & \\
\hline & 50 & $10 \pm 0.0^{\mathrm{a}}$ & $114.9 \mathrm{X}^{2} 2.9^{*}$ & $106.66 \pm 5.8^{\mathrm{e}}$ & $10.0 \pm .00^{\mathrm{a}}$ & \\
\hline & 25 & $10 \pm 0.0^{\mathrm{a}}$ & & $214 \pm 0.0^{\mathrm{h}}$ & $10.3 \pm 2.9^{\mathrm{a}}$ & \\
\hline & 12.5 & $10 \pm 0.0^{\mathrm{a}}$ & & $250 \pm 0.0^{\mathrm{i}}$ & $10.0 \pm 0.0^{\mathrm{a}}$ & \\
\hline \multirow{5}{*}{ TP-BT } & 150 & $53.3 \pm 0.6^{\mathrm{c}}$ & & $100 \pm 0.0^{\mathrm{e}}$ & $50.0 \pm 0.0^{\mathrm{b}}$ & \multirow{4}{*}{$169 \mathrm{X}^{2} 18.8^{*}$} \\
\hline & 100 & $0^{\mathrm{a}}$ & & $153 \pm 0.0^{\mathrm{g}}$ & $0.0^{\mathrm{a}}$ & \\
\hline & 50 & $0^{\mathrm{a}}$ & $164.5 \mathrm{X}^{2} 21.1^{*}$ & $260.7 \pm 1.15^{\mathrm{i}}$ & $0.0 \pm 0.0^{\mathrm{a}}$ & \\
\hline & 25 & $0^{\mathrm{a}}$ & & $260.7 \pm 1.15^{\mathrm{i}}$ & $0.0 \pm 0.0^{\mathrm{a}}$ & \\
\hline & 12.5 & $0^{\mathrm{a}}$ & & $260.7 \pm 0.00^{\mathrm{i}}$ & $0.0 \pm 0.00^{\mathrm{a}}$ & - \\
\hline TP-USM & 50 & $85 \pm 5.0^{\mathrm{e}}$ & - & $8 \pm 0.00^{\mathrm{a}}$ & $100.0 \pm 0.0^{\mathrm{d}}$ & - \\
\hline TP- FA & 50 & $20 \pm 0.0^{\mathrm{a}}$ & - & $300 \pm 0.0^{j}$ & $20.0 \pm 0.0^{\mathrm{a}}$ & - \\
\hline$B$-Sitosterol + Stigmasterol & 50 & $50 \pm 5^{c}$ & - & $100 \pm 0.0^{\mathrm{e}}$ & $50 \pm 0.0^{\mathrm{b}}$ & - \\
\hline $50 \%$ DMSO- ETOH (C-) & - & $0^{\mathrm{a}}$ & - & $347.00 \pm 0.00^{j}$ & $0.0 \pm 0.0^{\mathrm{a}}$ & - \\
\hline Deltamethrin $(\mathrm{C}+)$ & $50 \mu \mathrm{g} / \mathrm{ml}$ & $80.0 \pm 10.0^{\mathrm{e}}$ & - & $14 \pm 1.5^{\mathrm{a}}$ & $95.0 \pm 0.0^{\mathrm{d}}$ & - \\
\hline
\end{tabular}

Different superscripts in the same column represent a difference $(p<0.05)$. CH= crude hydroethanolic, $\mathrm{HX}=\mathrm{n}$-hexane, EA= ethyl acetate, $\mathrm{BT}=$ butanol, $\mathrm{USM}=$ unsaponifiable matter, FA= fatty acids DMSO: dimethyl sulphoxide, EtOH= ethanol, $\mathrm{C}-=$ negative control, $\mathrm{C}+=$ Positive control. Data are expressed as mean \pm standard deviation. 
TP-EA extract achieved $70 \%$ and $50 \%$ adult mortality at 100 and $150 \mathrm{mg} / \mathrm{ml}$ concentration, respectively, which were significantly different from both positive and negative control groups. At lower concentrations, it was inactive. Moreover, egg masses reached $250.00 \pm 0.00 \mathrm{mg} / 10$ females at $1.25 \%$ concentration and decreased gradually by increasing concentration till reached $43.3 \pm$ $31.8 \mathrm{mg} / 10$ females at $15 \%$ concentration. Egg mass was reduced significantly with the untreated $(p \leq 0.05)$ in all used concentrations but still significantly larger than deltamethrin group

TP-BT fraction showed 53\% mortalities $(p \leq 0.05)$ at $150 \mathrm{mg} / \mathrm{ml}$. However, no lethal effect at lower concentrations was recorded. Egg mass was reduced significantly with the negative control $(p \leq 0.05)$ in all tested concentrations but still significantly larger than deltamethrin group.

$B$-sitosterol + stigmasterol $(50 \mathrm{mg} / \mathrm{ml})$ showed $50.0 \pm$ $5 \%$ adulticidal activity. Egg mass was reduced significantly with the untreated $(p \leq 0.05)$ to $100 \mathrm{mg} / 10$ females. However, Egg masses were noticed even at the highest concentrations of EtOAc, BT, $50 \mathrm{mg} / \mathrm{ml} \beta$-sitosterol+stigmasterol, and deltamethrin $50 \mu \mathrm{g} /$ $\mathrm{ml}$, the deposited egg mass decreased significantly $(p \leq 0.05)$ at all treatments of $T$. portulacastrum L. In the control untreated group, mortality was $0 \%$ and ticks deposited egg mass about $347.00 \pm$ $0.00 \mathrm{mg} / 10$ females after 72 hours (Fig. 2, Table 2). $\mathrm{EC}_{50}$ of adult ticks was $69.4,45.7$, and $114.9,164.5 \mathrm{mg} / \mathrm{ml}$ in TP-CH, TP-HX, TP-EA, and TP-BT group, respectively.

\section{The effect on larvae of $R$. annulatus}

Findings of $T$. portulacastrum L. were matched with its adulticidal activity against $R$. annulatus. The mortality\% was significantly $(p \leq 0.05)$ variable among different extracts. It reached $100 \%(p \leq 0.05)$ in TP-CH and TP-HX fraction at 100 and 150 $\mathrm{mg} / \mathrm{ml}$ and decreased to $50 \%$ at $25 \mathrm{mg} / \mathrm{ml}$. Also, TP-EA fraction achieved good larvicidal activity at the highest concentration $(70.0 \pm 0.0 \%)$ and $50.0 \pm 0.0 \%$ at $100 \mathrm{mg} / \mathrm{ml}(p \leq 0.05)$. While, larvicidal activity of TP-EA was $10.0 \pm 0.0 \%$ and non-significantly different with untreated control group at lower concentrations. However, butanol had $50.0 \pm 0.0 \%(p \leq 0.05)$ larvicidal activity at its highest concentration. On the contrary, no lethal effect was

Table 2. Percentage of inhibition of the AChE enzyme (mean + standard deviation) using extracts of $\mathrm{AC}$ and $\mathrm{TP}$ in comparison with galantamine.

\begin{tabular}{lccc}
\hline \multirow{2}{*}{ Treatment } & \multicolumn{3}{c}{ Concentration (mg/ml) } \\
\cline { 2 - 4 } & $53.67 \pm 1.07^{\mathrm{f}}$ & $63.25 \pm 4.80^{\mathrm{e}}$ & $78.34 \pm 0.37^{\mathrm{d}}$ \\
\hline AC-CH & $90.46 \pm 1.21^{\mathrm{b}}$ & $96.30 \pm 0.60^{\mathrm{a}}$ & $99.33 \pm 0.34^{\mathrm{a}}$ \\
TP-CH & $91.67 \pm 2.88^{\mathrm{b}}$ & $93.49 \pm 3.27^{\mathrm{b}}$ & $98.21 \pm 1.38^{\mathrm{a}}$ \\
TP-HX & $79.05 \pm 1.27^{\mathrm{d}}$ & $87.91 \pm 1.41^{\mathrm{c}}$ & $91.94 \pm 3.94^{\mathrm{b}}$ \\
TP-EA & $89.53 \pm 1.31^{\mathrm{b}}$ & $88.00 \pm 0.43^{\mathrm{c}}$ & $89.77 \pm 0.47^{\mathrm{b}}$ \\
TP-BT & $93.46 \pm 1.26^{\mathrm{b}}$ & $95.28 \pm 1.81^{\mathrm{a}}$ & $96.47 \pm 0.44^{\mathrm{a}}$ \\
20-hydroxyecdysone & $59.04 \pm 1.38^{\mathrm{f}}$ & $71.64 \pm 1.55^{\mathrm{e}}$ & $76.69 \pm 3.50^{\mathrm{d}}$ \\
TP- FA & $63.04 \pm 3.50^{\mathrm{f}}$ & $75.22 \pm 1.16^{\mathrm{d}}$ & $77.83 \pm 1.14^{\mathrm{d}}$ \\
TP-USM & $57.92 \pm 1.85^{\mathrm{f}}$ & $66.04 \pm 6.09^{\mathrm{e}}$ & $84.62 \pm 1.00^{\mathrm{c}}$ \\
B-Sitosterol +Stigmasterol & $95.50 \pm 0.50^{\mathrm{a}}$ & $97.51 \pm 0.48^{\mathrm{a}}$ & $99.97 \pm 0.58^{\mathrm{a}}$ \\
Galantamine & &
\end{tabular}

Values, which have not the same superscript symbol, are significantly different at $p<0.05 . \mathrm{CH}=$ crude hydroethanolic; $\mathrm{HX}=\mathrm{n}$-hexane, $\mathrm{EA}=$ ethyl acetate, $\mathrm{BT}=$ butanol, $\mathrm{USM}=$ unsaponifiable matter, $\mathrm{FA}=$ fatty acids: Data are expressed as mean \pm standard error noticed in larvae that were subjected to BT at concentration of $(10 \%, 5 \%, 2.5 \%$, and $1.25 \%) . \beta$-sitosterol+stigmasterol $(50 \mathrm{mg} /$ $\mathrm{ml})$ showed $50.0 \pm 0.0 \%$ larvicidal activity $(p \leq 0.05)$, while the positive control Deltamethrin $50 \mu \mathrm{g} / \mathrm{ml}$ showed $95.00 \% \pm 0.0$ $(p \leq 0.05)$. On the contrary, non-significant larval mortalities were noticed in ticks that were subjected to $A$. canariensis $\mathrm{CH}$ extract at 100 and $150 \mathrm{mg} / \mathrm{ml}$ concentrations and the untreated control group (50\% DMSO-ETOH). EC E $_{50}$ of larvae were 24, 34.6, 114.7, and 169 $\mathrm{mg} / \mathrm{ml}$ in TP-CH, TP-HX, TP-EA, and TP-BT group, respectively.

\section{Effect of tested plant extracts, fractions or constituents on AChE activity}

As indicated in Figure 2, Table 2, TP-CH, TP-HX and 20-hydroxyecdysone produced the most potent inhibitory effect on AChE activity $(99.33 \pm 0.34 \%, 98.21 \pm 1.3 \%$, and $96.47 \pm 0.44 \%$ inhibition at highest concentration) which was concentration dependent; these effects were comparable to the effects of standard AChE inhibitor, galantamine. According to the classification of Vinutha et al. (2007), >50\% inhibition of AChE activity is classified as a potent inhibitor.

TP-EA fraction and TP-BT are arranged in the second order as the potent $\mathrm{AChE}$ activity inhibitors. $\mathrm{AC}-\mathrm{CH}$ was the less potent in affecting AChE inhibitory activity, especially at concentrations 0.25 and $0.5 \mathrm{mg} / \mathrm{ml}$. The $\mathrm{TP}-\mathrm{CH}$ at three different concentrations $(0.25,0.5$, and $1 \mathrm{mg} / \mathrm{ml})$ produced a highly significant increase in $\mathrm{AChE}$ percent inhibition as compared with the corresponding concentrations of AC-CH. TP-HX was more effective than TP-EA and TP-BT fractions at the three different concentrations. The TP-USM of hexane extract seemed to be more effective on AChE percent inhibition than TP-FA at concentrations $0.25,0.5$ and $1 \mathrm{mg} / \mathrm{ml}$; however, the effect was not significant $(p>0.05$; LSD) at concentrations 0.25 and $1 \mathrm{mg} / \mathrm{ml}$. The $\beta$-sitosterol-stigmasterol mixture induced a significant dose dependent anti-AChE effect ( $p \leq 0.05$; LSD). Concerning oneway ANOVA, the effect between plant ingredients on AChE activity percent inhibition at different concentrations was highly significant ( $p \leq 0.01$; F-probability).

\section{GC-MS analysis of USM}

GC-MS analysis of TP-USM revealed the presence of trimethy-12-pentadecanone (13.83\%), 2-phenyldodecane $(7.70 \%)$, 5 -phenylundecane $(4.07 \%)$, as major hydrocarbons and phytol $(4.67 \%)$ which is acyclic diterpene, stigmasterol $(2.59 \%), \beta$ - and sitosterol $(1.67 \%)$ as major sterols as shown in Table 3.

\section{DISCUSSION}

Terrestrial plants and their products are promising source of effective acaricides (Pavela et al., 2016). Being a mixture of several compounds, it is hard for the insect to develop resistance against the plant extracts, because of several mechanisms of killing. In addition, being eco-friendly, easily degradable are additional advantages. Here, we investigate the activity of hydro alcoholic extracts of two herbs of the family Aizoaceae: $T$. portulacastrum L. and A. canariensis L. against $R$. annulatus (the bovine tick in Egypt). A biologically-guided isolation of active plant metabolites was our strategy as shown in Figure 1. In this strategy, chromatography and bioassay are parallel; fractionation and purification of only active fractions are done. 
Table 3. Chemical compounds identified by GC-MS analyses of the USM of the $n$-hexane fraction obtained from Trianthema portulacastrum $\mathrm{L}$ herb.

\begin{tabular}{cccll}
\hline Peak & RRT & {$[\mathbf{M}]+\bullet(\%)$} & Molecular formula & Compound \\
\hline 1 & 0.73 & $232(4.07)$ & $\mathrm{C}_{17} \mathrm{H}_{28}$ & 5-phenylundecane \\
2 & 0.75 & $232(2.18)$ & $\mathrm{C}_{17} \mathrm{H}_{28}$ & 4-Phenylundecane \\
3 & 0.85 & $246(7.70)$ & $\mathrm{C}_{18} \mathrm{H}_{30}$ & 2-Phenyldodecane \\
4 & 0.85 & $260(3.82)$ & $\mathrm{C}_{19} \mathrm{H}_{32}$ & 6-PhenylTridecane \\
5 & 0.89 & $268(13.83)$ & $\mathrm{C}_{18} \mathrm{H}_{36} \mathrm{O}$ & Trimethy-12-Pentadecanone \\
6 & 1 & $296(4.67)$ & $\mathrm{C}_{20} \mathrm{H}_{40} \mathrm{O}$ & Phytol \\
8 & 1.44 & $386(1.54)$ & $\mathrm{C}_{27} \mathrm{H}_{46} \mathrm{O}$ & Cholesterol \\
9 & 1.5 & $400(0.72)$ & $\mathrm{C}_{28} \mathrm{H}_{48} \mathrm{O}$ & Campesterol \\
10 & 1.52 & $412(2.59)$ & $\mathrm{C}_{29} \mathrm{H}_{48} \mathrm{O}$ & Stigmasterol \\
11 & 1.59 & $414(1.67)$ & $\mathrm{C}_{29} \mathrm{H}_{50} \mathrm{O}$ & $\beta$-sitosterol \\
\hline
\end{tabular}

RRT= Relative Retention Time to Phytol; $[\mathrm{M}]+\bullet=$ Molecular ion; \%: peak area.

In this study, TP-CH was active while AC-CH was not, so the TP only was extracted on large scale and fractionated using solvents of different polarities (HX, EA, and BT) to divide the natural constituents into groups according to their polarities. The prepared extracts are monitored by bioassay. TP-HX and TPEA showed promising activities at $150 \mathrm{mg} / \mathrm{ml}(100 \%$ and $70 \%$, respectively) in both adult and larval immersion tests. The most effective fraction (TP-HX) was then subjected to saponification to separate the USM (steroids, triterpenoids and hydrocarbons) from the fatty acids. Both USM and FA were retested for their acaricidal activity where USM showed $85 \pm 5 \%$ adult mortality which still insignificantly different from deltamethrin; the used chemical pyrethroid. The lowest EC 50 of adult ticks was 69.4 and 45.7 $\mathrm{mg} / \mathrm{ml}$ in TP-CH and TP-HX, respectively. Meanwhile, in TP-EA and TP-BT groups, the EC 50 of adult ticks were 114.9, and 164.5 $\mathrm{mg} / \mathrm{ml}$, respectively.

TP-USM was subjected to GC-MS analysis (Table 3) and phytol was present which was previously reported to contribute to the pesticidal and nematicidal activity of Cynodon dactylon with palmitic acid, ethyl hexadecanoate, and ethyl stearate (Jananie et al., 2011). In addition, stigmasterol $(2.59 \%)$ and $\beta$-sitosterol (1.67\%) were present as major sterols. Chromatographic purification of TP-USM was performed to isolate major constituents for evaluation of acaricidal activity. A mixture of $\beta$-sitosterol-stigmasterol (1:1) was isolated as shown by NMR spectroscopy and measuring the integration of the proton signals at $\delta_{\mathrm{H}} 5.03 \mathrm{ppm}$ characteristic for stigmasterol and $\delta_{\mathrm{H}} 5.35 \mathrm{ppm}$ for each stigmasterol and $\beta$-sitosterol. Calculation of the percentage was done through comparing both integration values. and then the mixture was used in immersion tests. In our previous study, $\beta$-sitosterol $(25 \mathrm{mg} / \mathrm{mL}$ ) showed $86.66 \pm 5 \%$ and $91.66 \pm 2.88 \%$ adulticidal and larvicidal activity, respectively (Moawad et al., 2017). It is the same concentration of $\beta$-sitosterol present in this mixture $(50 \mathrm{mg} / \mathrm{ml}$ of a mixture of two compounds with equal proportions). Since the mixture was less active than $\beta$-sitosterol alone, this indicates that the presence of stigmasterol in the mixture reduced the activity. Stigmasterol is $\Delta^{24} \beta$-sitosterol which might produce antagonistic effect with $\beta$-sitosterol due to structure similarity and they are a common non-separable mixture of natural products (Lokadi Pierre, 2015). Our finding is also supported by the study on Culex quinquefasciatus larvae in which a mixture of phytosterols were more active when compared to stigmasterol alone (Gade et al., 2017). Steroids are important constituent in tick cuticle and the observed shrinkage in TP-CH, TP-HX, and TP-USM may be due to interference of steroids synthesis by the phytosterols of $T$. portulacastrum herb. The high lipophilicity of TP-USM constituents may contribute to their acaricidal effect through facilitating the penetration of the cuticle of adult tick that is composed mainly of waxes or lipids (Diehl et al., 1982).

On the other hand, TP-EA was also subjected to chromatographic isolation and 20-hydroxyecdysone was isolated (Banerji et al., 1971) but its amount was not sufficient for immersion test and only AChE inhibition assay was performed. TPBT showed adulticidal activity only at the highest concentration but no activity at lower concentrations. This also may be due to its 20-hydroxyecdysone content.

20-hydroxyecdysone is a main representative of ecdysteroids which are arthropod steroid hormones controlling development and reproduction and are synthesized from cholesterol (Rewitz and Gilbert, 2008). Ecdysteroids bind to ecdysone receptor and many chemicals may be agonists or antagonists (Minakuchi et al., 2003).

The anticholinesterase activity of the active extracts and fractions were evaluated in order to find the possible relation between the acaricidal effect and the AChE inhibitory property. The AChE inhibition Activity was correlated to immersion test results and it may be one of the mechanisms of acaricidal activity.

Our results indicated that the TP-CH and TP-HX as well as 20-hydroxyecdysone produced the most potent inhibitory effects on AChE activity which are comparable with the standard $\mathrm{AChE}$ inhibitory drug, galantamine. On the other hand, A. canariensis crude hydroethanolic extract (AC$\mathrm{CH})$ showed lower $\mathrm{AChE}$ inhibitory activity. In parallel with this result, Sesuvium portulacastrum (Aizoaceae) showed $50 \%$ inhibitory activity to AChE as indicated by Suganthy et al. (2009). The inhibition of AChE may prolong the neuronal excitation induced by acetylcholine, which may in turn result in neuromuscular paralysis and death of the parasite. This attribution was supported by Tan et al. (2011). T. portulacastrum exhibited potent cholinesterase inhibitory activity attributable to the presence of the isolated sterols and of significance in the acaricidal activity. On comparison with data in literature, sterol mixture was better AChE inhibitor than its pure compound although stigmasterol has shown a good inhibitory effect on the enzyme (Gade et al., 2017).

\section{CONCLUSION}

Steroids, located in the $n$-hexane, EA and BT fractions, are part of the bioactive compounds responsible for T. portulacastrum acaricidal effects which may be mediated, at least in part, via $\mathrm{AChE}$ inhibitory activities. With the previously reported in vivo safe intake of $T$. portulacastrum L. herb; it provides a promising herb for veterinary use for control of vector-borne diseases and as safer alternatives in the control of tick populations. Additional studies are necessary for the evaluation of 20-hydroxyecdysone activity and in vivo studies are also needed for the confirmation of the in-vitro effect 


\section{ACKNOWLEDGMENT}

The parasitology work done in this study was financially supported by a grant funded by Project Funding and Granting Unit, Scientific Research Development Unit, Beni-Suef University.

\section{CONFLICT OF INTEREST}

The authors indicate that there is no conflict of interest

\section{AUTHORS' CONTRIBUTIONS}

This work was carried out in collaboration between all the authors. Abeer Moawad, Hala Abuzaid, Hetta, and Rabab Mohammed wrote the protocol, performed the chromatographic isolation, and spectroscopic analysis. Waleed M. Arafa designed and performed the acaricidal study. Osama Ahmed designed and performed the Anticholinesterase study. All authors wrote the first draft of the manuscript and managed the analyses of the results and the literature searches. All authors read and approved the final manuscript.

\section{REFERENCES}

Abdelgaleil SAM, Badawy ME, Mahmoud NF, Marei, AEM. Acaricidal activity, biochemical effects and molecular docking of some monoterpenes against two-spotted spider mite (Tetranychus urticae Koch). Pestic Biochem Physiol, 2019; 156:105-15. Available via https://doi. org/10.1016/j.pestbp.2019.02.006.

Aboelhadid SM, Mahran HA, El-Hariri HM, Shokier KM. Rhipicephalus annulatus (Acari: Ixodidae) control by Nigella sativa, Thyme and spinosad preparations. J Arthropod Borne Dis, 2016; $2: 148-58$

Akkol EK, Orhan IE, Yeilada E. Anticholinesterase and antioxidant effects of the ethanol extract, ethanol fractions and isolated flavonoids from Cistus laurifolius L. leaves. Food Chem, 2012; 131:62631. Available via https://doi.org/10.1016/j.foodchem.2011.09.041.

Al-Rajhy DH, Alahmed AM, Hussein HI, Kheir SM. Acaricidal effects of cardiac glycosides, azadirachtin and neem oil against the camel tick,Hyalomma dromedarii (Acari: Ixodidae). Pest Manag Sci, 2003; 59:1250-54. Available via https://doi.org/10.1002/ps.748.

Amin E, Moawad A, Hassan H. Biologically-guided isolation of leishmanicidal secondary metabolites from Euphorbia peplus L. Saudi Pharm J, 2017; 25:236-40. Available via https://doi.org/10.1016/j. jsps.2016.06.003.

Badawy MEI, El-Arami SA, Abdelgaleil SAM. Acaricidal and quantitative structure activity relationship of monoterpenes against the twospotted spider mite, Tetranychus urticae. Experiment Appl Acarol, 2010; 52:261-74.

Banerji A, Chintalwar GJ, Joshi NK, Chadha MS. Isolation of ecdysterone from indian plants. Phytochemistry 1971; 10:2225-26. Available via https://doi.org/10.1016/S0031-9422(00)97227-3.

Chaturvedula VSP, Prakash I. Isolation of stigmasterol and $\beta$-sitosterol from the dichloromethane extract of Rubus suavissimus. Int Curr Pharm J, 2012; 1:239-42. Available via Christie WW. Preparation of ester derivatives of fatty acids for chromatographic analysis. In: William WC (ed.). Advances in lipid methodology - two, Oily Press, Dundee, The Scottish Crop Research Institute, Invergowrie, Dundee, Scotland, pp. 69 $111,1993$.

Chungsamarnyart N, Jansawan W. Effect of Tamarindus indicus L. Against the Boophilus microplus. Kasetsart J (Nat Sci), 2001; 35:34-9.

Diehl PA, Aeschlimann A, Obenchain FD. Tick reproduction: oogenesis and oviposition. Physiol Ticks, 1982; 1:277-350. Available via https://doi.org/10.1016/B978-0-08-024937-7.50014-7.

Ellman GL, Courtney KD, Andres V, Featherstone RM. A new and rapid colorimetric determination of acetylcholinesterase activity. Biochem Pharmacol, 1961; 7:88-95. Available via https://doi. org/10.1016/0006-2952(61)90145-9.

El-Zemity S, Rezk H, Farok S, Zaitoon A. Acaricidal activities of some essential oils and their monoterpenoidal constituents against house dust mite, Dermatophagoides pteronyssinus (Acari: Pyroglyphidae). J Zhejiang Univ Sci B, 2006; 7:957-62. Available via https://doi.org/10.1631/ jzus.2006.B0957.

Ferreira FM, Delmonte CC, Novato TLP, Monteiro CMO, Daemon E, Vilela FMP, Amaral, MPH. Acaricidal activity of essential oil of Syzygium aromaticum, hydrolate and eugenol formulated or free on larvae and engorged females of Rhipicephalus microplus. Med Vet Entomol, 2018; 32:41-47. Available via https://doi.org/10.1111/mve.12259.

Flamini G. Acaricides of natural origin, personal experiences and review of literature (1990-2001). Stud Nat Prod Chem, 2003; 28:381451. Available via https://doi.org/10.1016/S1572-5995(03)80146-1.

Flor-Weiler LB, Behle RW, Stafford KC. Susceptibility of four tick species, Amblyomma americanum, Dermacentor variabilis, Ixodes scapularis, and Rhipicephalus sanguineus (Acari: Ixodidae), to nootkatone from essential oil of grapefruit. J Med Entomol, 2011; 48:322-26.

Freije A, Alkhuzai J, Al-Laith AA. Fatty acid composition of three medicinal plants from Bahrain: new potential sources of $\gamma$-linolenic acid and dihomo- $\gamma$-linolenic. Ind Crops Prod, 2013; 43:218-24. Available via https://doi.org/10.1016/j.indcrop.2012.07.021.

Gade S, Rajamanikyam M, Vadlapudi V, Nukala KM, Aluvala R, Giddigari C, Karanam, NJ, Barua NC, Pandey R, Upadhyayula VSV, Sripadi P, Amanchy R, Upadhyayula SM. Acetylcholinesterase inhibitory activity of stigmasterol \& hexacosanol is responsible for larvicidal and repellent properties of Chromolaena odorata. Biochim Biophys Acta Gen Subj, 2017; 1861:541-50. Available via https://doi.org/10.1016/j. bbagen.2016.11.044.

Girault JP, Lafont R. The complete ${ }^{1} \mathrm{H}-\mathrm{NMR}$ assignment of ecdysone and 20-hydroxyecdysone. J Insect Physiol, 1988; 34:701-6. Available via https://doi.org/10.1016/0022-1910(88)90080-7. https://doi. org/10.3329/icpj.v1i9.11613.

Hussain A, Khan MN, Iqbal Z, Sajid MS, Khan MK. Anthelmintic activity of Trianthema portulacastrum L. and Musa paradisiaca L. against gastrointestinal nematodes of sheep. Vet Parasitol, 2011; 179:92-9. Available via https://doi.org/10.1016/j.vetpar.2011.02.022.

Jananie R, Priya V, Vijayalakshmi K. Determination of bioactive components of Cynodon dactylon by GC-MS analysis. New York Sci J, $2011 ; 4: 16-20$.

Jayaraman M, Senthilkumar A, Venkatesalu V. Evaluation of some aromatic plant extracts for mosquito larvicidal potential against Culex quinquefasciatus, Aedes aegypti, and Anopheles stephensi. Parasitol Res, 2015; 114:1511-18. Available via https://doi.org/10.1007/s00436-015-4335-0.

Kamal AM, Ziada AA, Soliman RF, Selim MA. Chemical investigation of lipoidal matter of Ficus craterostoma. J Adv Pharm Res, 2017; 547:150-54.

Klafke GM, Sabatini GA, De Albuquerque TA, Martins JR, Kemp DH, Miller RJ, Schumaker TTS. Larval immersion tests with ivermectin in populations of the cattle tick Rhipicephalus (Boophilus) microplus (Acari: Ixodidae) from State of Sao Paulo, Brazil. Vet Parasitol, 2006; 142:386-90. Available via https://doi.org/10.1016/j.vetpar.2006.07.001.

Lokadi Pierre L. Isolation and characterisation of stigmasterol and $\beta$-sitosterol from Odontonema Strictum (Acanthaceae). J Innov Pharm Biol Sci, 2015; 2;88-95.

Minakuchi C, Nakagawa Y, Kamimura M, Miyagawa H. Binding affinity of nonsteroidal ecdysone agonists against the ecdysone receptor complex determines the strength of their molting hormonal activity. Eur J Biochem, 2003; 270:4095-104. Available via https://doi.org/10.1046/ j.1432-1033.2003.03801.x

Moawad A, Mohammed R, Arafa W. Biologically-guided Isolation of acaricidal phytosterols: an in vitro study against Rhipicephalus (B.) annulatus ticks infesting cattle in Egypt. Eur J Med Plants Brazil, 2017; 18:1-9. Available via https://doi.org/10.9734/EJMP/2017/32702. 
Mohammed R, El-Hawary SS, Abo-Youssef AM. Biological investigation of some wild aizoaceae and chenopediaceae species growing in Egypt. J Nat Prod (India), 2012; 5:193-206.

Pavela R, Canale A, Mehlhorn H, Benelli G. Application of ethnobotanical repellents and acaricides in prevention, control and management of livestock ticks: a review. Res Vet Sci, 2016; 109:1-9. Available via https://doi.org/10.1016/J.RVSC.2016.09.001.

Rewitz KF, Gilbert LI. Daphnia Halloween genes that encode cytochrome P450s mediating the synthesis of the arthropod molting hormone: evolutionary implications. BMC Evol Biol, 2008; 8:1-8. Available via https://doi.org/10.1186/1471-2148-8-60.

Ribeiro VLS, Vanzella C, Moysés F dos S, Santos JC dos, Martins JRS, Poser GL von, Siqueira IR. Effect of Calea serrata Less. n-hexane extract on acetylcholinesterase of larvae ticks and brain Wistar rats. Vet Parasitol, 2012; 189:322-26. Available via https://doi.org/10.1016/j. vetpar.2012.04.033.

Rodriguez-Vivas RI, Alonso-Díaz, MA, Rodríguez-Arevalo F, Fragoso-Sanchez H, Santamaria VM, Rosario-Cruz R. Prevalence and potential risk factors for organophosphate and pyrethroid resistance in Boophilus microplus ticks on cattle ranches from the State of Yucatan, Mexico. Vet Parasitol, 2006; 136:335-42. Available via https://doi. org/10.1016/j.vetpar.2005.05.069.

Santos FO, Lima HG, de Souza S, Rosa S, das Mercês NB, Serra TM, Uzeda RS, Reis IMA, Botura MB, Branco A, Batatinha MJM. In vitro acaricide and anticholinesterase activities of digitaria insularis (Poaceae) against Rhipicephalus (Boophilus) microplus. Vet Parasitol, 2018; 255:102106. Available via https://doi.org/10.1016/j.vetpar.2018.04.003.

Sharma AK, Kumar R, Kumar S, Nagar G, Singh NK, Rawat SS, Dhakad ML, Rawat AKS, Ray DD, Ghosh S. Deltamethrin and cypermethrin resistance status of Rhipicephalus (Boophilus) microplus collected from six agro-climatic regions of India. Vet Parasitol, 2012; 188:337-45. Available via https://doi.org/10.1016/j.vetpar.2012.03.050.

Singh SP, Kamaraju R, Thomas T. Mosquito larvicidal properties of aqueous and acetone extracts of Trianthema portulacastrum Linn. (Family: Aizoaceae) against vector species of mosquitoes. J Commun Dis, $2011 ; 43: 237-41$.
Suganthy N, Pandian SK, Devi KP. Cholinesterase inhibitory effects of Rhizophora lamarckii, Avicennia officinalis, Sesuvium portulacastrum and Suaeda monica: mangroves inhabiting an Indian coastal area (Vellar Estuary). J Enzyme Inhib Med Chem, 2009; 24:702-07. Available via https://doi.org/10.1080/14756360802334719.

Tan F, Wang L, Wang J, Wu X, Zhu H, Jiang L, Tao S, Zhao K, Yang Y, Tang X. Enhanced pesticide sensitivity of novel housefly actylcholinesterases: a new tool for the detection of residual pesticide contamination. Bioprocess Biosyst Eng, 2011; 34:305-14. Available via https://doi.org/10.1007/s00449-010-0472-0.

Van Leeuwen T, Vontas J, Tsagkarakou A, Dermauw W, Tirry L. Acaricide resistance mechanisms in the two-spotted spider mite Tetranychus urticae and other important Acari: a review. Insect Biochem Mol Bio, 2010; 40:563-72.

Vinutha B, Prashanth D, Salma K, Sreeja SL, Pratiti D, Padmaja R, Radhika S, Amit A, Venkateshwarlu K, Deepak M. Screening of selected Indian medicinal plants for acetylcholinesterase inhibitory activity. J Ethnopharmacol, 2007; 109:359-63. Available via https://doi.org/10.1016/j. jep.2006.06.014.

Yadav E, Yadav PK, Verma A. Trianthema portulacastrum (L.): an important traditional herb. Ann Pharm Pharmaceut Sci, 2016; 7:46-52. Available via https://doi.org/10.15740/HAS/APPS/7.1/46-52.

How to cite this article:

Moawad A, Abuzaid H, Arafa WM, Ahmed O, Hetta M, Mohammed R. Anticholinesterase and acaricidal activities of steroids isolated from Trianthema portulacastrum L. against Rhipicephalus annulatus tick. J Appl Pharm Sci, 2020; 10(04):047-055. 